\title{
Synthesis and Performance Evaluation of Anti Temperature and Salt Resistant Polymer Filtrate Reducer
}

\author{
Zhu Zhu ${ }^{1}$, Huaiyuan Long', Dichen Tan ${ }^{1}$, Song Wang1 ${ }^{*}$, Zuwen Wang ${ }^{2}$, Shunyuan Zhang ${ }^{3}$, Yu Deng4 \\ ${ }^{1}$ School of Chemical and Environmental Engineering, Yangtze University, Jingzhou, China \\ ${ }^{2}$ Chuanqing Drilling Engineering Company Underground Operation Company, Xi'an, China \\ ${ }^{3}$ China National Petroleum Corporation Engineering Technology Research Institute Co. Ltd., Beijing, China \\ ${ }^{4}$ Drilling Fluid Technical Service Company of Chuanqing Drilling Engineering Co., Ltd., Chengdu, China \\ Email: 446907182@qq.com, *1508871707@qq.com
}

How to cite this paper: Zhu, Z., Long, H.Y., Tan, D.C., Wang, S., Wang, Z.W., Zhang, S.Y. and Deng, Y. (2019) Synthesis and Performance Evaluation of Anti Temperature and Salt Resistant Polymer Filtrate Reducer. Open Journal of Yangtze Gas and Oil, 4, 248-257.

https://doi.org/10.4236/ojogas.2019.44020

Received: July 22, 2019

Accepted: October 7, 2019

Published: October 10, 2019

Copyright $\odot 2019$ by author(s) and Scientific Research Publishing Inc. This work is licensed under the Creative Commons Attribution International License (CC BY 4.0).

http://creativecommons.org/licenses/by/4.0/ (c) (i) Open Access

\begin{abstract}
In the experiment, the filtrate loss of synthetic fluid loss control fluid was recorded in room temperature and high temperature in the composite brine base and sodium chloride brine base slurry, and compared with the filtrate loss before base polymer addition. In this way, the effect of filtration loss and salt resistance and temperature resistance of synthetic polymers were evaluated. The influence of the synthesized polymer on the rheological properties of the composite brine was also evaluated by determining the viscosity of the drilling fluid added to the base slurry and polymer. In the end, the structure of the synthetic polymers was characterized through the infrared spectrum, which initially analyzed through the mechanism of its function in reducing the filter loss. Finally, the products produced according to the recipe are given to the site and added to the two wells to record the drilling fluid performance data.
\end{abstract}

\section{Keywords}

Polymer, Filtrate Reducer, Rheological Characteristic, Monomer, Synthesis, Drilling Fluid

\section{Introduction}

The filtrate reducer is commonly used oilfield chemicals additives in oilfield drilling fluid. During the process of drilling, drilling fluid filtrate invasion into the stratum will cause mud shale hydration swelling and reservoir damage, even cause hole instability and various complicated hole problems when the situation 
is very serious. The purpose of adding filtrate reducer is formatting a low permeability, flexibility and dense filter cake to reduce the filtration loss, which could provide the stable performance of drilling fluid and the underground safety. Therefore, filtrate reducer becomes the most active research and development drilling fluid treating agent with the largest production and sales volume [1] [2] [3] [4] [5].

\section{Experimental}

\subsection{Materials and Apparatus}

As shown in Table 1, the materials and chemicals used for the experiments are Filtrate reducer (Homemade XR-X), 2-Acrylamide-2-methylpro panesulfonic acid (AMPS), acrylic acid (AA), N-isopropylacrylamide (NIPAM), nano-calcium bentonite, calcium bentonite, evaluation soil (industrial grade), Ammonium persulfate, sodium bisulfite, sodium carbonate, sodium bicarbonate, calcium chloride, magnesium chloride, sodium chloride (analytical reagent).

Table 1. Experimental drugs.

\begin{tabular}{|c|c|c|}
\hline Chemicals & Purities & Suppliers \\
\hline AMPS & Industrial grade & Hubei HANC new technology co. LTD \\
\hline AA & Industrial grade & Hubei HANC new technology co. LTD \\
\hline NIPAM & Industrial grade & Hubei HANC new technology co. LTD \\
\hline Nano-calcium bentonite & Industrial grade & Hubei modern petroleum technology co. LTD \\
\hline Calcium bentonite & Industrial grade & Hubei modern petroleum technology co. LTD \\
\hline Evaluation soil & Industrial grade & Hubei modern petroleum technology co. LTD \\
\hline Ammonium persulfate & Analytical reagent & Shanghai chemical reagent co. LTD \\
\hline Sodium bisulfite & Analytical reagent & Shanghai chemical reagent co. LTD \\
\hline Sodium bicarbonate & Analytical reagent & Shanghai chemical reagent co. LTD \\
\hline Calcium chloride & Analytical reagent & Shanghai chemical reagent co. LTD \\
\hline Magnesium chloride & Analytical reagent & Shanghai chemical reagent co. LTD \\
\hline Sodium chloride & Analytical reagent & Shanghai chemical reagent co. LTD \\
\hline
\end{tabular}

The apparatus used to conduct the experiment comprise spulverizer, dryer, heating roller furnace, high speed homogenizer, thermostat water bath cauldron, Six-speed rotatory viscometer, SD-multiple medium pressure filter tester, HTHP high pressure high temperature filter tester, infrared spectrometer, NETZSCH TG 209 F1 type thermogravimetric analyzer, etc.

\subsection{Sample Preparations}

$100 \mathrm{~g}$ of AMPS was dissolved in distilled water and $40 \mathrm{~g}$ of AA was added into 
the mixture, a certain concentration of sodium hydroxide solution is added to adjust the PH to 7. NIPAM was added proportionally until fully dissolved at $35^{\circ} \mathrm{C}$, then Nanometer calcium bentonite and initiating agent was added and stirred evenly, After 50 minutes' reaction, $\mathrm{N}_{2}$ gas was injected for protection. It was shattered after 8 hour's vacuum drying at $110^{\circ} \mathrm{C}$. Finally XR-X series powder filtrate reducer sample was obtained.

\subsection{Test Methods}

Prepare compound brine base:

$1000 \mathrm{ml}$ distilled water $+45.70 \mathrm{~g} \mathrm{NaCl}+7.40 \mathrm{~g} \mathrm{CaCl}_{2}+19.70 \mathrm{~g} \mathrm{MgCl}_{2}$ as the combination, $350 \mathrm{ml}$ compound brine is taken, $9.00 \mathrm{~g} \mathrm{Na}_{2} \mathrm{CO}_{3}$ and $149.00 \mathrm{~g}$ calcium bentonite are added under the extraordinary speed stirring condition, then we could get the compound brine. Take $350 \mathrm{ml}$ brine of the corresponding $\mathrm{NaCl}$ concentration we have compounded. $1.00 \mathrm{~g} \mathrm{NaHCO}_{3}$ and $35.00 \mathrm{~g}$ evaluation soil are added under the high speed stirring condition that is brine base. The polymer we have already compounded is added, carry on the filtration determination under the room temperature condition and high temperature aging condition. Verify whether the synthetic polymer meets the actual field or not. Use of six-speed rotatory viscometer to evaluate the viscosity changes before and after adding the polymer drilling fluid, analyze how the synthetic sample influence the rheological property of drilling fluid. And keep on IR characterization to the synthetic polymer.

\section{Results and Discussions}

\subsection{Performance Evaluations of Antitemperature and Salt Resistant}

$0.7 \% \mathrm{XR}-\mathrm{X}$ series sample in the compound brine and brine base which we have just compounded should be added, seal under $25^{\circ} \mathrm{C} \pm 3{ }^{\circ} \mathrm{C}$ the condition maintains $24 \mathrm{~h}$, measure room temperature API filter loss. 1.5\% XR-X series sample in the compound brine and brine base which we have just compounded are added, seal under $25^{\circ} \mathrm{C} \pm 3^{\circ} \mathrm{C}$ the condition maintains $6 \mathrm{~h}$, after high speed stirring, aging at $220^{\circ} \mathrm{C}$, After cooling to room temperature, carrying on HTHP filter loss $\left(3.5 \mathrm{MPa}, 150^{\circ} \mathrm{C}\right)$ and rheological property measurement. The results are shown in Table $2-4$ respectively.

Table 2. Effect of XR-X on filtration loss of compound brine.

\begin{tabular}{ccccc}
\hline Sample & Room temperature condition & $\begin{array}{c}\text { API filter } \\
\text { loss } / \mathrm{ml}\end{array}$ & $\begin{array}{c}\text { High temperature } \\
\text { condition }\end{array}$ & $\begin{array}{c}\text { HTHP } \\
\text { filter loss } / \mathrm{ml}\end{array}$ \\
\hline blank & Place $24 \mathrm{~h}$ at room temperature & 220 & $220^{\circ} \mathrm{C} / 16 \mathrm{~h}$ & 150 \\
XR-1 & Place $24 \mathrm{~h}$ at room temperature & 7.0 & $220^{\circ} \mathrm{C} / 16 \mathrm{~h}$ & 9.3 \\
XR-2 & Place $24 \mathrm{~h}$ at room temperature & 7.8 & $220^{\circ} \mathrm{C} / 16 \mathrm{~h}$ & 9.4 \\
XR-3 & Place $24 \mathrm{~h}$ at room temperature & 7.0 & $220^{\circ} \mathrm{C} / 16 \mathrm{~h}$ & 9.9 \\
XR-4 & Place $24 \mathrm{~h}$ at room temperature & 7.2 & $220^{\circ} \mathrm{C} / 16 \mathrm{~h}$ & 9.5 \\
\hline
\end{tabular}


Table 3. Effect of XR-4 on filtration loss of brine.

\begin{tabular}{ccccc}
\hline $\mathrm{NaCl} / \%$ & Room temperature condition & $\begin{array}{c}\text { API filter } \\
\text { loss } / \mathrm{ml}\end{array}$ & $\begin{array}{c}\text { High temperature } \\
\text { condition }\end{array}$ & $\begin{array}{c}\text { HTHP filter } \\
\text { loss } / \mathrm{ml}\end{array}$ \\
\hline 5 & Place 24 h at room temperature & 6.2 & $220^{\circ} \mathrm{C} / 16 \mathrm{~h}$ & 9.2 \\
10 & Place 24 h at room temperature & 7.3 & $220^{\circ} \mathrm{C} / 16 \mathrm{~h}$ & 10.2 \\
15 & Place 24 h at room temperature & 7.8 & $220^{\circ} \mathrm{C} / 16 \mathrm{~h}$ & 10.8 \\
20 & Place 24 h at room temperature & 8.0 & $220^{\circ} \mathrm{C} / 16 \mathrm{~h}$ & 11.4 \\
25 & Place 24 $\mathrm{h}$ at room temperature & 13.5 & $220^{\circ} \mathrm{C} / 16 \mathrm{~h}$ & 17.5 \\
\hline
\end{tabular}

Table 4. Effect of XR-X on rheological properties of compound brine.

\begin{tabular}{ccccc}
\hline \multirow{2}{*}{ Sample } & \multicolumn{2}{c}{ Room-temperature condition $\left(20^{\circ} \mathrm{C}\right)$} & High temperature condition $\left(220^{\circ} \mathrm{C}\right)$ \\
\cline { 2 - 5 } & $\begin{array}{c}600 \mathrm{r} / \mathrm{min} \\
\text { calibration }\end{array}$ & $\begin{array}{c}300 \mathrm{r} / \mathrm{min} \\
\text { calibration }\end{array}$ & $\begin{array}{r}600 \mathrm{r} / \mathrm{min} \\
\text { calibration }\end{array}$ & $\begin{array}{c}300 \mathrm{r} / \mathrm{min} \\
\text { calibration }\end{array}$ \\
\hline Blank & 11 & 5 & 12 & 7 \\
XR-1 & 15 & 8 & 14 & 9 \\
XR-2 & 14 & 7 & 15 & 9 \\
XR-3 & 16 & 8 & 13 & 8 \\
XR-4 & 15 & 7 & 15 & 9 \\
\hline
\end{tabular}

From Tables 2-4, we can see XR-X series filtrate reducer has good capacity of filter loss in compound brine and $20 \% \mathrm{NaCl}$ brine base, also the ability of anti temperature, which can reach $220^{\circ} \mathrm{C}$.

\subsection{IR Characterization}

The XR-2 of XR-X series sample will be chosen, we will carry on infrared spectrum analysis after purify and dry it by using acetone, as shown in Figure 1. Secondary amide characteristic absorption center is at $3423 \mathrm{~cm}^{-1}$, stretching vibration absorption center of $-\mathrm{CH}_{2}$ - is at $2933 \mathrm{~cm}^{-1}$, sulfonic group characteristic absorption centered respectively at $1186 \mathrm{~cm}^{-1}, 1116 \mathrm{~cm}^{-1}, 1042 \mathrm{~cm}^{-1}$, stretching vibration absorption center of $\mathrm{C}-\mathrm{S}$ is at $628 \mathrm{~cm}^{-1}$, the characteristic absorption center of $\mathrm{C}=\mathrm{O}$ is at $4.1654 \mathrm{~cm}^{-1}$ [6] [7] [8].

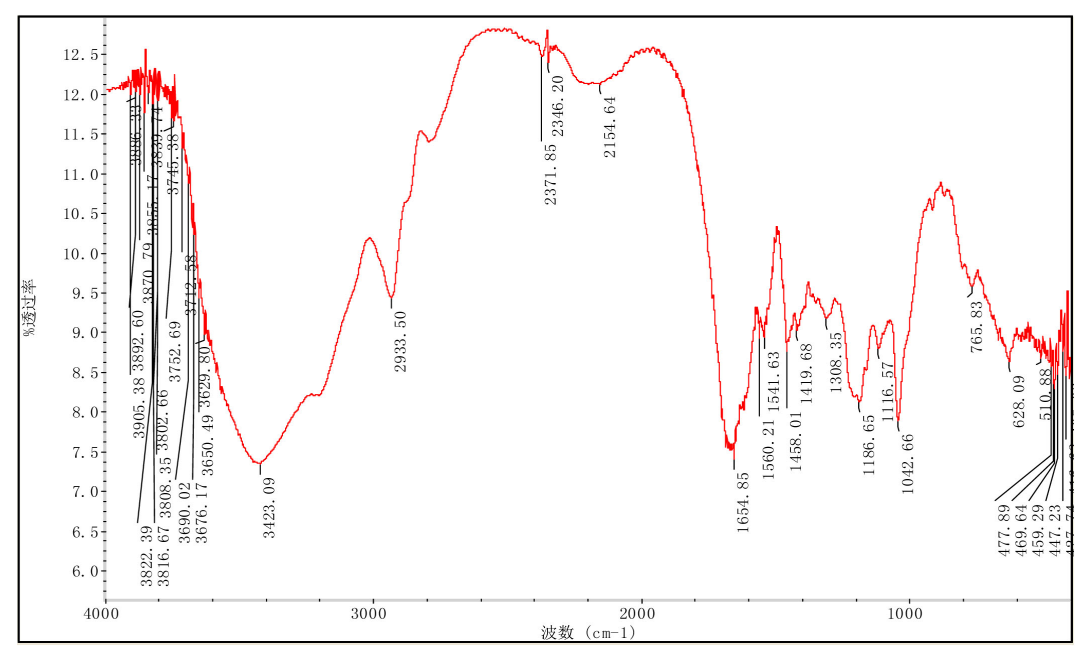

Figure 1. Infrared absorption spectra of XR-2. 
From Figure 1, we can see the sample contain Carboxyl, secondary amides, sulfonic group and other functional molecule groups, Carboxyl and sulfonic group have strong capacity of hydratability. Amide has good ability of clay adsorption. Sulfonic group anti temperature and calcium resistant well. The C-C structure of the polymer itself has excellent thermal stability. Therefore the synthesis polymer owns the good performance of anti temperature, salt resistant and filtrate loss.

\subsection{Thermogravimetric Analyses}

In the process of heating to high temperature, the polymer molecule may occur physical and chemical changes such as dehydration, decomposition, and oxidation. The structure of the molecule will be destroyed obviously, resulting in change the performance of drilling fluid filtrate reducer, thus affecting the rheology of the whole drilling fluid system. In the process, the mass of the polymer may change. Therefore, Thermogravimetric analysis (TG) can be utilized to investigate the thermal stability of the filtrate reducer [9] [10] [11].

Using NETZSCH TG 209 F1 type thermogravimetric analyzer to test the thermal stability of polymer filtrate reducer in nitrogen gas, heating rate 10 $\mathrm{K} / \mathrm{min}$, gas flow rate $50 \mathrm{~mL} / \mathrm{min}$, heating rate of $\mathrm{K} / \mathrm{min}$, the results of TG analysis are shown in Figure 2 [11] [12] [13].

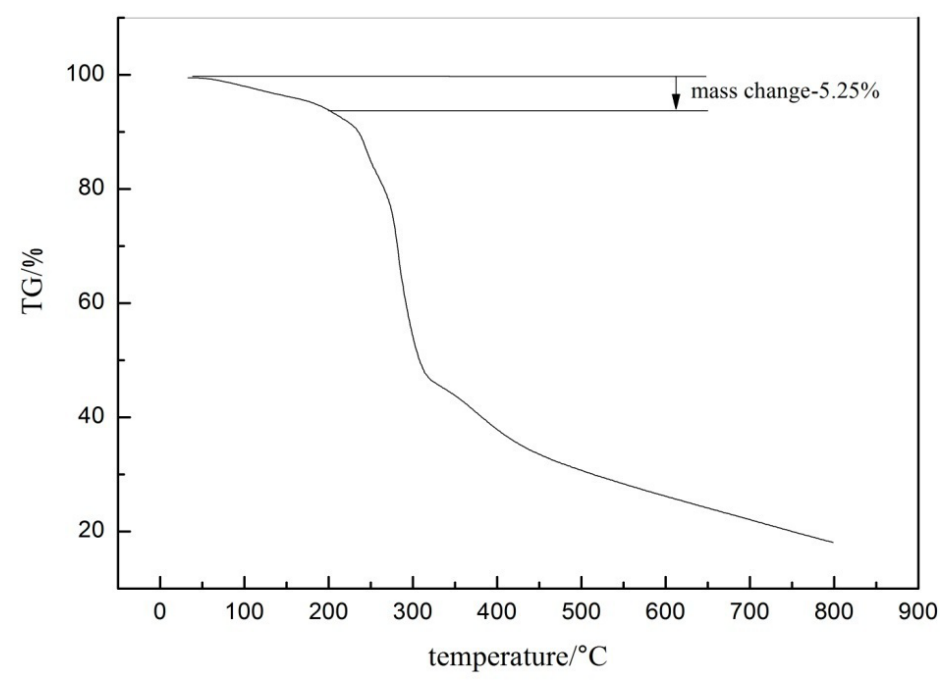

Figure 2. Thermogravimetric analysis of polymer fluid loss.

From Figure 2, we can see the mass of XR-2 polymer filtrate reducer loss slowly with the increase of temperature, After the temperature surpasses $250^{\circ} \mathrm{C}$, the mass start to lose rapidly, However, mass loss of polymer filtrate reducer in the range of $0^{\circ} \mathrm{C}-200^{\circ} \mathrm{C}$ is relatively slow. However, the mass loss of polymer filtrate reducer in the range of $0^{\circ} \mathrm{C}-200^{\circ} \mathrm{C}$ is relatively slow. The mass loss rate is only $5.25 \%$ when the temperature reaches $220^{\circ} \mathrm{C}$ or so. It is indicated that the synthetic polymer filtrate reducer can withstand $220^{\circ} \mathrm{C}$ high temperature [14] [15] [16]. 


\section{The Application of Oil Well Site}

\subsection{Brief Geological Conditions of Oil Well Site}

Biyang 432 well is situated in the south of Chengdian Village, Gaodian, Biyang County, Henan Province. The Biyang 431 well is situated in Henan Province with convenient transportation. Its structure is situated in the lower two southwestern wings of the lower Biyang depression. The main purpose of the two wells is to carry out and preliminaries explore the hydrocarbon-bearing properties of the tight sandstone and fault-lithologic trap in the three lower part of the fault nucleus of the 189 well district, and to search for new geological reserves. The strata of this district are composed of Quaternary Plain Group, Neogene Fenghuangzhen Formation and Paleogene Walnut Group from top to bottom.

1) Plains Group and Fenghuangzhen Formation: Reddish-pale yellow mudstone, light gray-greyish red gravel sandstone is present in the form of unequal thickness interbedded layers with loose strata.

2) Liao Zhuang group: variegated, greyish gravel sandstone and gray, reddish brown sandstone are present in the form of unequal thickness interbedded layers.

3) A nuclear section: gray, gray-brown mudstone and gray-white, light gray gravel sandstone, fine sandstone is found in the form of unequal thickness interbedded layers.

4) The second section of the atomic: gray, dark gray, gray-brown mudstone, shale and off-white, light gray gravel sandstone, fine sandstone are present in the form of unequal thickness interbed.

5) The third section of the core is mainly light gray, brownish gray, taupe gravel sandstone, gravel sandstone, fine sandstone, argillaceous siltstone, gray mudstone, dark gray mudstone, beige mudstone, shale are present in the form of unequal thickness interbedded layers.

\subsection{Drilling Requirements}

1) Before drilling, mix bentonite slurry $80 \mathrm{~m}^{3}$, add circulating water and $0.3 \%$ soda ash in a circulating tank, and then, $5 \%$ to $8 \%$ bentonite will be added to the mixing hopper in the mixing condition, mix the prehydration above $24 \mathrm{~h}$ and set aside for reserve.

2) Develop a coating liquid with a concentration of $0.5 \%-1.0 \%$ and a volume of $20 \mathrm{~m}^{3}$. During the drilling process, prepared glue is uniformly added to the drilling fluid according to the cycle, and the drilling fluid performance is adjusted: the density is less than $1.05 \mathrm{~g} / \mathrm{cm}^{3}$, and the viscosity is between $50 \mathrm{~s}$ and $80 \mathrm{~s}$.

3) Depending on the lithology of the formation and the size of the drill cuttings, the size of the screen should be selected cautiously. The mesh number should be chosen to meet the minimum loss of drilling fluid to maximize the removal of solid particles in the slurry.

4) Take full advantage of solid-control equipment to strictly control the drilling fluid in useless solid content. 
5) Reserve an appropriate amount of plugging material is utilized to deal with the loss.

6) Preparation of high viscosity drilling fluid in the liquid storage tank for the wellbore cleaning.

7) After drilling, turn the large displacement power to wash the well and fully circulate the drilling fluid to reduce the sand content to less than $0.5 \%$. When there is no sand in vibrating screen basically, make a short drilling operation.

8) After short trip, fully circulate 2 cycles to 3 cycles, clean the wellbore with high-viscosity drilling fluid to ensure smooth casing.

9) In the process of drilling, PAC141 and H4-HPAN polymer colloid are supplemented to keep the polymer concentration and enhance the inhibition of drilling fluid in time.

10) Maintain the drilling fluid treatment agent normally, and make the XR-X filtrate loss agent match into the glue liquid according to the design formula as far as possible, add it into the drilling fluid according to the cycle period, and try not to directly add the dry powder treatment agent into the circulating drilling fluid.

11) Adding 2\% content of $\mathrm{ZRH}-2$ into the inclined section to increase the lubrication performance of the system.

12) Drilling to 2600 - $2800 \mathrm{~m}$ or so, adding $\mathrm{XR}-\mathrm{X}$ fluid loss agent drilling fluid system to improve the drilling fluid system temperature resistance, reduce the high temperature filtration.

13) Before entering the target reservoir, the performance of drilling fluid should be strictly controlled in the designed range, especially the density and the loss of the filtrate cannot exceed the design requirements. The API filtration loss should be controlled within $5 \mathrm{ml}$ and the HTHP filtration loss within $15 \mathrm{ml}$, to protect the reservoir.

14) Make full use of solid-control equipment, control the poor solid phase and low-density solid phase in the drilling fluid strictly, always make the drilling fluid sand content less than $0.5 \%$.

15) Deal with drilling fluid in advance before the drill is finished, and maintain uniform and stable performance of the drilling fluid, generally speaking, operators do not have to make large-scale treatment. The drilling fluid is circulated more than 2 cycles before drilling to fully clean the well, so as to ensure the smooth electrical measurement.

\subsection{Performance and Application of Well Drilling Fluid in Oil Well}

The ammonium salt water loss agent ( $0.8 \%$ glue liquid) was used before $2635 \mathrm{~m}$ of 432 oil well, The amount of XR-X fluid loss additive ( $0.5 \%$ glue solution) after $2635 \mathrm{~m}$ was added after $2635 \mathrm{~m}$ of No.432 oil well, and the solution concentration of $3183 \mathrm{~m}-4643 \mathrm{XR}-\mathrm{X}$ drops is $0.8 \%$, no foaming and tackifying, Oil well use of low viscose liquid ( $1 \% \mathrm{XR}-\mathrm{X}$ water loss agent glue) after $4643 \mathrm{~m}$. As can be seen from Table 5, after using XR-X fluid loss agent drilling fluid, drilling fluid API filtration lost from $12.0 \mathrm{ml}$ to $5.0 \mathrm{ml}$, HTHP filtration loss from $16.0 \mathrm{ml}$ to 
$10.0 \mathrm{ml}$, The filtrate loss of drilling fluid is controlled steadily and effectively, the other indicators of liquid meet the requirements, better meet the drilling requirements.

Table 5. No. 432 well drilling fluid performance.

\begin{tabular}{ccccccccc}
\hline $\begin{array}{c}\mathrm{TD} \\
\mathrm{m}\end{array}$ & $\begin{array}{c}\rho \\
\mathrm{g} / \mathrm{cm}^{3}\end{array}$ & $\begin{array}{c}\mathrm{Fv} \\
\mathrm{s}\end{array}$ & $\begin{array}{c}\mathrm{AV} \\
\mathrm{mPa} . \mathrm{s}\end{array}$ & $\begin{array}{c}\mathrm{PV} \\
\mathrm{mPa} . \mathrm{s}\end{array}$ & $\begin{array}{c}\mathrm{YP} \\
\mathrm{Pa}\end{array}$ & $\begin{array}{c}\mathrm{Gel} \\
\mathrm{Pa} / \mathrm{Pa}\end{array}$ & $\begin{array}{c}\mathrm{API} \mathrm{FL} \\
\mathrm{ml}\end{array}$ & $\begin{array}{c}\mathrm{HTHP} \mathrm{PL}_{\mathrm{FL}} \\
\mathrm{ml}\end{array}$ \\
\hline 1815 & 1.16 & 42 & 22 & 16 & 6 & $1.5 / 3.5$ & 13.0 & 16.0 \\
2185 & 1.18 & 44 & 24.5 & 17 & 7.5 & $2 / 5$ & 12.0 & 15.5 \\
2310 & 1.18 & 45 & 23 & 16 & 7 & $1 / 5$ & 12.0 & 15.5 \\
2656 & 1.25 & 47 & 23.5 & 16 & 7.5 & $1.5 / 4.5$ & 4.5 & 9.0 \\
3183 & 1.27 & 48 & 25 & 17.5 & 7.5 & $1.5 / 5$ & 4.5 & 9.0 \\
3532 & 1.29 & 50 & 26 & 18 & 8 & $2 / 6$ & 4.6 & 9.0 \\
4010 & 1.32 & 52 & 29 & 21 & 8 & $1.5 / 6.5$ & 4.8 & 9.6 \\
4643 & 1.36 & 56 & 29.5 & 22 & 7.5 & $1.5 / 7.5$ & 4.9 & 9.8 \\
5215 & 1.40 & 58 & 31 & 22.5 & 8.5 & $2 / 9$ & 5.0 & 10.0 \\
\hline
\end{tabular}

Adding 1\% XR-X drops to the $2851 \mathrm{~m}$ of the 431 oil well, As shown in Table 6, the API filtration loss of drilling fluid in wells was reduced from $7.6 \mathrm{ml}$ to 5.0 $\mathrm{ml}$, the filtration loss of HTHP from $15.2 \mathrm{ml}$ to $10 \mathrm{ml}$, The fluid loss performance is obvious, which can effectively control the fluid loss of the drilling fluid and control the fluid loss within a reasonable range to ensure underground safety.

Table 6. No. 431 well drilling fluid performance.

\begin{tabular}{ccccccccc}
\hline $\begin{array}{c}\mathrm{TD} \\
\mathrm{m}\end{array}$ & $\begin{array}{c}\rho \\
\mathrm{g} / \mathrm{cm}^{3}\end{array}$ & $\begin{array}{c}\mathrm{Fv} \\
\mathrm{s}\end{array}$ & $\begin{array}{c}\mathrm{AV} \\
\mathrm{mPa} \cdot \mathrm{s}\end{array}$ & $\begin{array}{c}\mathrm{PV} \\
\mathrm{mPa} \cdot \mathrm{s}\end{array}$ & $\begin{array}{c}\mathrm{YP} \\
\mathrm{Pa}\end{array}$ & $\begin{array}{c}\mathrm{Gel} \\
\mathrm{Pa} / \mathrm{Pa}\end{array}$ & $\begin{array}{c}\mathrm{API} \mathrm{FL} \\
\mathrm{ml}\end{array}$ & $\begin{array}{c}\mathrm{HTHP} \mathrm{FL}_{\mathrm{FL}} \\
\mathrm{ml}\end{array}$ \\
\hline 2784 & 1.21 & 44 & 27 & 19 & 8 & $2.5 / 5$ & 7.6 & 15.2 \\
2851 & 1.22 & 45 & 28 & 21 & 7 & $3 / 6.5$ & 4.0 & 9.2 \\
3210 & 1.25 & 52 & 28 & 20 & 8 & $2.5 / 6$ & 3.8 & 9.0 \\
3740 & 1.24 & 52 & 32.5 & 22 & 10.5 & $3 / 8$ & 4.2 & 9.4 \\
4111 & 1.28 & 54 & 33 & 24 & 9 & $2.5 / 8$ & 4.6 & 9.6 \\
4697 & 1.36 & 64 & 34 & 25 & 9 & $2.5 / 13$ & 4.8 & 9.7 \\
5170 & 1.39 & 62 & 36.5 & 26 & 10.5 & $3 / 14$ & 4.9 & 9.7 \\
5208 & 1.41 & 65 & 38 & 27 & 11 & $3.5 / 16$ & 5.0 & 10 \\
\hline
\end{tabular}

\section{Conclusions}

1) When the increment in the compound brine is $0.7 \%, \mathrm{XR}-\mathrm{X}$ series filtrate reducer has good capacity of filter loss, when the increment is $1.5 \%$, the anti temperature reaches $220^{\circ} \mathrm{C}$.

2) XR-X series filtrate reducer has little effect on viscidity of compound brine drilling fluid after room temperature and high temperature aging. It has to 
moderate effect on the rheology of drilling fluid.

3) When the increment in the brine base is $0.7 \%, \mathrm{XR}-\mathrm{X}$ series filtrate reducer could resist $20 \% \mathrm{NaCl}$. When the increment is $1.5 \%$, under the condition of $220^{\circ} \mathrm{C}$ high temperatures, it can play a very good role in filter loss.

4) Through infrared spectrum analysis, the polymer contains functional groups such as sulfonic acid, carboxyl group and amide. Therefore, the synthesis polymer owns the good performance of anti temperature, salt resistant and filtrate loss.

5) For thermogravimetric analysis, the synthesized polymer XR-X filtrate reducer can withstand $220^{\circ} \mathrm{C}$ high temperature.

6) Through the practical application of the two oil wells in the field, it is proved that the XR-X fluid loss product can effectively control the water loss of $5000 \mathrm{~m}$ deep well drilling fluid.

\section{Fund Project}

National Natural Science Foundation of China (41072109).

\section{Conflicts of Interest}

The authors declare no conflicts of interest regarding the publication of this paper.

\section{References}

[1] Amanullah, M., Ramasamy, J., Al-Arfaj, M.K. and Aramco, S. (2016) Application of an Indigenous Eco-Friendly Raw Material as Fluid Loss Additive. Journal of Petroleum Science and Engineering, 139, 191-197. https://doi.org/10.1016/j.petrol.2015.12.023

[2] (2002) Evaluation and Application of Anti-High Temperature Drilling Fluid Filtrate Reducer JHW. Drilling Fluid and Completion Fluid, Fine Petrochemical Industry Progress, 2, 10-12.

[3] Julio, M., del Lago, P., Filial de Pdvsa, S.A., et al. (2007) Using a Low-Salinity High-Performance Water-Based Drilling Fluid for Improved Drilling Performance in Lake Maracaibo. SPE 110366.

[4] Wang, X.G., Yang, X.H., et al. (2009) Research and Application Progress of Anti-High Temperature Drilling Fluid Filtrate Reducer at Home and Abroad. Drilling Fluid and Completion Fluid, 14, 116-121.

[5] Ramirez, M.A., Benaissa, S., Ragnes, G., et al. Aluminum-Based HPWBM Successfully Replaces Oil-Based Mud to Drill Exploratory Well in the Magellan Strait, Argentina. SPE 108213.

[6] Taugbl, K., Magne Jakobsen T., Svanes, K., Lilledal, L. and Henning, J. (2004) The Completion of Subsea Production Wells Eased by the Use of a Unique, High-Density, Solids-Free, Oil Based Completion Fluid. SPE 87126.

[7] Zou, J., Qu, J., Lu, G., Tan, W.-L. and Zhu, H.-J. (2005) A Novel Fluidloss Additive BXF-200L for Oil Field Cement and Its Application. Drilling Fluid \& Completion Fluid, 22, 20-23.

[8] An, Y., Jiang, G.C., Qi, Y.R., et al. (2015) Synthesis of Nano-Plugging Agent Based on AM/AMPS/NVP Terpolymer. Journal of Petroleum Science and Engineering, 
135, 505-514. https://doi.org/10.1016/j.petrol.2015.10.014

[9] Knapen, E. and van Genmert, D. (2009) Cement Hydration and Microstructure Formation in the Presence of Water-Soluble Polymers. Cement and Concrete Research, 39, 6-13. https://doi.org/10.1016/j.cemconres.2008.10.003

[10] Hamida, T., Kuru, E. and Pickard, M. (2010) Filtration Loss Characteristics of Aqueous Waxy Hull-Less Barley (WHB) Solutions. Journal of Petroleum Science and Engineering, 72, 33-41. https://doi.org/10.1016/j.petrol.2010.02.006

[11] AL-Ansari, A., Yadav, K., Aramce, S., et al. (2005) Diverse Application of Unique High-Performance Water-Based Mud Technology in the Middle East. SPE/IADC 97314, 12-14.

[12] Reynolds, D., Popplestone, A., Gwynne, P. and Reynolds, D. (2005) High Performance, Water-Based Drilling Fluid Helps Achieve Early Oil with Lower Capital Expenditure. SPE 96798.

[13] Tao, W., Jie, Y., Sun, Z., Wang, L. and Wang, J. (2011) Solution and Drilling Fluid Properties of Water Soluble AM-AA-SSS Copolymers by Inverse Microemulsion. Journal of Petroleum Science and Engineering, 78, 334-337. https://doi.org/10.1016/j.petrol.2011.06.027

[14] Morton, K., Bomar, B., Schiller, M., et al. (2005) Selection and Evaluation Criteria for High-Performance Drilling Fluids. SPE 96342, 9-10. https://doi.org/10.2523/96342-MS

[15] Zhao, Z.G., Pu, X.L., Xiao, L., et al. (2015) Synthesis and Properties of High Temperature Resistant and Salt Tolerant Filtrate Reducer N,N-Dimethylacrylamid-e 2-Acrylamido-2Methyl-1-Propyl Dimethyl Diallyl Ammonium chloriden-Vinylpyr-Rolidone Quadripolymer. Journal of Polymer Engineering, 35, 627-635. https://doi.org/10.1515/polyeng-2014-0260

[16] Bland, R., Mullen, G., Gonzalez, Y., Ernest Harvey, F. and Pless, M.L. (2006) HP/HT Drilling Fluids Challenge. SPE 103731. https://doi.org/10.2523/103731-MS 